\title{
Seh- und Hörtest für alle Ärzte in der Schweiz über 50 Jahre
}

EMH News Service

Die Lancet-Sonderausgabe von Januar 2015 schlug ein wie eine Bombe - und es gibt wohl keine Ärztin und keinen Arzt auf der Welt, die die Titelseite des Heftes noch nie gesehen haben (siehe Abb. 1[1]). Dessen Inhalt sorgte in der Tat für Zündstoff, soll doch fast die Hälfte aller Medikationsfehler und Fehldiagnosen auf visuelle Defizite der behandelnden Ärzte zurückzuführen sein.

\section{In Deutschland bereits Pflicht}

Die ersten politischen Reaktionen liessen nicht lange auf sich warten, am schnellsten reagierten wieder einmal die deutschen Behörden: Seit dem 1. April 2017 müssen sich in Deutschland niedergelassene Ärzte mit Versorgungsauftrag ab dem 51 . Lebensjahr obligatorisch alle fünf Jahre einem Sehtest unterziehen. Diese Tests werden, um die Unabhängigkeit zu bewahren, von den Technischen Überwachungsvereinen durchgeführt - also jenen Instanzen, die auch für die Motorfahrzeugkontrollen zuständig sind. In Deutschland spricht man daher auch vom "Ärzte-TÜV».

In der Schweiz bestand längere Zeit die Hoffnung, dass auf solche Tests verzichtet wird. Nun aber setzen die kantonalen Gesundheitsdirektionen sogar noch einen drauf. Ab dem 1. April 2019 wird für über 50-jährige Ärztinnen und Ärzte die Praxisbewilligung nur noch dann ausgestellt bzw. verlängert, wenn sie regelmässig einen Seh- und einen Hörtest vornehmen lassen. Schliesslich sei bei der Verwechslung von Medikamenten nicht nur «look-alike» ein Problem, sondern auch «sound-alike» (Beispiel Ciproxin und Cipralex). Böse Zungen allerdings unterstellen den kantonalen Behör-

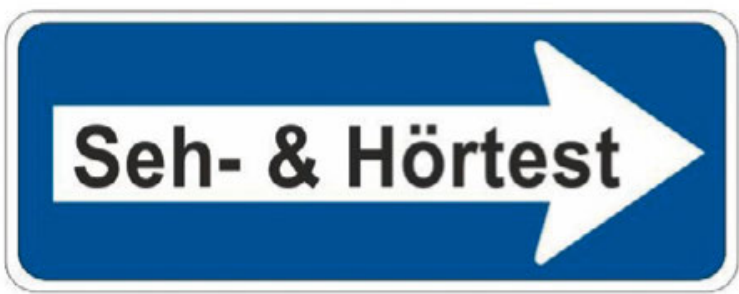

Bald für Ärztinnen und Ärzte in der Schweiz eine Selbstverständlichkeit - aber auch eine Einbahnstrasse?

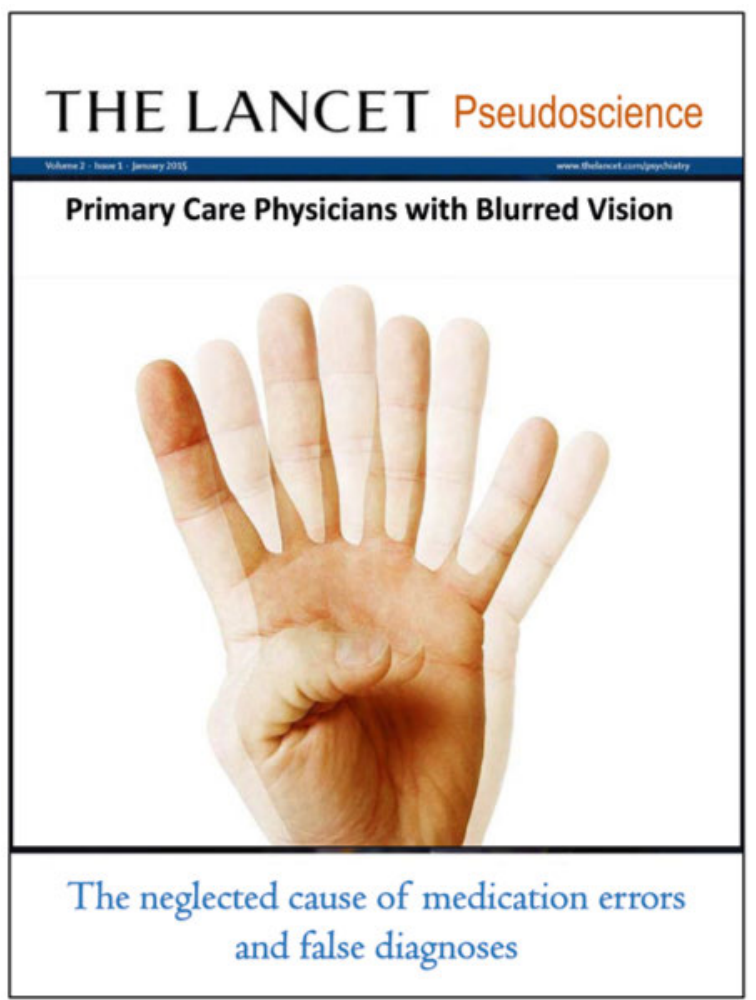

Titelseite der Lancet-Sonderausgabe von Januar 2015.

den, dass sie mit den Hörtests nur den Forderungen von Patientenorganisationen nachkommen (die den Ärzten grundsätzlich unterstellen, Patienten nicht richtig zuzuhören).

Beide Tests sollen durch die kantonsärztlichen Dienste durchgeführt werden, und hier hat man sich wenigstens etwas einfallen lassen: Für die Sehtests werden Fotos von Funduskopien verwendet (mit unterschiedlichen pathologischen Befunden), für die Hörtests werden Geräusche von Herzvitien eingespielt. Neben der optimalen Anpassung einer Seh- und Hörhilfe gibt es somit zusätzlich ein wenig Fortbildung und bei $80 \%$ richtigen Antworten 1 Kernfortbildungs-Credit für Allgemeine Innere Medizin.

\section{Literatur}

1 Lancet. Primary care physicians with blurred vision - the neglected cause of medication errors and false diagnoses. Special issue «Pseudoscience», January 2015. 